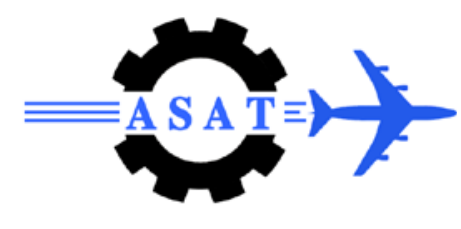

\title{
Analysis of Ferrite Coplanar Waveguide Transmission Line
}

\author{
M.A. Abdalla* ${ }^{*}$ H.A. Elregaily ${ }^{\dagger}$, and A.A. Mitkees ${ }^{+}$
}

\begin{abstract}
In this paper, we introduce detailed analysis of electromagnetic wave propagation along a planar ferrite coplanar waveguide transmission line. The analysis was done using the electromagnetic full wave of CPW transmission lines implemented on ferrite substrate. All the possible excitation directions of the applied DC magnetic bias were studied. The a nalytical study $\mathrm{w}$ as $\mathrm{v}$ erified using full $\mathrm{w}$ ave simulations of electromagnetic $\mathrm{w}$ aves propagation along different $t$ ypes of ferrite $\mathrm{c}$ oplanar $\mathrm{w}$ aveguide. $\mathrm{T}$ he $\mathrm{s}$ imulation $\mathrm{r}$ esults $\mathrm{c}$ onfirmed $\mathrm{t}$ he propagation characteristics derived in the analytical study.
\end{abstract}

Keywords: Ferrite, Coplanar waveguide, Full wave analysis, Permeability

\section{Introduction}

The ne ed $\mathrm{f}$ or de vices $\mathrm{w}$ ith di fferent $\mathrm{m}$ agnetic pr operties $\mathrm{r}$ equires $\mathrm{t}$ he us e of a $\mathrm{m}$ agnetic material. Magnetic materials c omprise ferromagnetic and ferrimagnetic ma terials (Ferrites). Examples of ferromagnetic materials are iron and nickel. Ferrites are similar to ferromagnetic materials except ferrites usually have lower saturation magnetizations. Ferrites are found in compounds, with complex crystal structures, whose raw material is turned into powder which can be formed int o a hard ceramic ma terial. Ferrites ar e us ually compared in terms of saturation magnetization rather th an susceptibility or relative permeability. Also, ferrite is a magnetic anisotropic material whose anisotropy properties a re induced by the applying DC magnetic bias field.

Ferrites ha ve a $l$ ot of attractive $p$ roperties $f$ or $m$ icrowave engineering. First, they have tuneable and nonreciprocal properties due to their magnetic properties. Second, as mentioned above, ferrites allows the propagation of electromagnetic within them due to their electrical insulator properties. Also, they ha ve greater e lectrical $r$ esistivity tha $n$ ferromagnets $w$ hich introduce much lower eddy current losses. Finally, they can be fabricated in different shapes at 1 ow cos $\mathrm{t} t$ echniques. Therefore, ferrites are $\mathrm{w}$ idely us ed at $\mathrm{m}$ icrowave frequency applications such as circulators, i solators, and gyrators [2-4]. Thanks to the ferrite electrical insulator properties that ensure total penetration of electromagnetic fields, ferrite substrates are $w$ idely us ed in many dispersive and nonreciprocal $m$ icrowave $m$ agnetic $p l$ anar ci rcuits depending on the applied DC magnetic bias.

\footnotetext{
* maaabdallah@,gmail.com Đr, Electronic Engineering Department, MTC University, Cairø

$\dagger$ Egyptian Armed Forces, Egypt.

Egyptian Armed Forces, Egypt.
} 
In this paper, we introduce mathematical an alysis of electromagnetic wave propagation in a planar ferrite coplanar waveguide (CPW) transmission line. This mathematical study has been done us ing the electromagnetic full wave a nalysis of ferrite CPW transmission lines. Such analysis has be en explained in details for a ferrite $m$ icrostrip TL in [1] but ha ve not be en formulated in CPW cas e. The explanation will be introduced in de tails in this paper for different directions of applied DC magnetic bias.

\section{General}

It is understood that a microwave signal can propagate through a ferrite differently in different directions, i.e. nonreciprocal propagation, c ontrolled by the applied DC magnetic bias. The relative permeability tensor is dependent on the direction of ferrite magnetization as [3]

$$
\begin{array}{ll}
{[\mu]=\left[\begin{array}{ccc}
\mu & j k & 0 \\
-j k & \mu & 0 \\
0 & 0 & 1
\end{array}\right]} & (\hat{Z} \text { Bias }) \\
{[\mu]=\left[\begin{array}{ccc}
\mu & 0 & -j k \\
0 & 1 & 0 \\
j k & 0 & \mu
\end{array}\right]} & (\hat{Y} \text { Bias }) \\
{[\mu]=\left[\begin{array}{ccc}
1 & 0 & 0 \\
0 & \mu & j k \\
0 & -j k & \mu
\end{array}\right]} & (\hat{X} \text { Bias })
\end{array}
$$

where

$$
\begin{aligned}
& \mu=\frac{\omega_{h m}^{2}-\omega^{2}}{\omega_{h}^{2}-\omega^{2}} \\
& k=\frac{\omega \omega_{m}}{\omega_{h}^{2}-\omega^{2}}
\end{aligned}
$$

The Larmor frequency (gyromagnetic resonance frequency) $\left(\omega_{h}\right)$, the magnetization frequency $\left(\omega_{m}\right)$, and $\left(\omega_{h m}\right)$ are defined as

$$
\begin{aligned}
& \omega_{h}=\mu_{0} \gamma H_{0} \\
& \omega_{m}=\mu_{0} \gamma M_{s} \\
& \omega_{h m}=\mu_{0} \gamma \sqrt{H_{0}\left(H_{0}+M_{s}\right)}
\end{aligned}
$$

where $\gamma$ is the gyromagnetic ratio, the ratio between the spin magnetic moment to the spin angular moment, equals $1.759 \times 10^{11} \mathrm{C} / \mathrm{Kg}$.

\section{TEM Mode Propagation in a Normally Magnetized Ferrite CPW TL}

In this section, we present the mathematical analysis of a normally magnetized ferrite CPW TL, i. e. m agnetized pe rpendicular to the di rection of propagation. F or a $n$ e lectromagnetic wave propagating along a ferrite CPW TL, there are two possible normal directions. First, the 
DC magnetic bias direction is horizontal, i. e., it is along the CPW strip width. Second, it is vertical which means that it is along the substrate thickness. These two possible DC magnetic bias di rections a re s hown in Figure 1. First, we pr esent the ma thematical a nalysis of the horizontally m agnetized ferrite CPW T L while the ot her case can be co nsidered in similar way. Then, the ferrite TL performance is verified numerically for both normal DC magnetic bias directions.

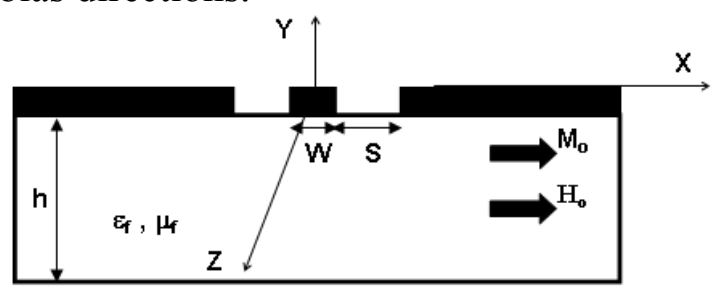

(a)

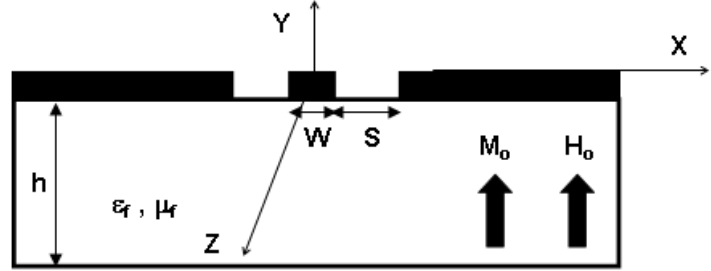

(b)

Figure 1 The front view of the CPW TL on ferrite substrate (a) Horizontally magnetized (b) Vertically magnetized.

\section{TEM Mathematical Analysis}

In this section, the full wave analysis technique of Maxwell's equations is used to derive the field components and the propagation parameters of a hor izontally biased ferrite CPW TL as shown in Figure 1 (a). The ferrite permeability tensor is expressed as in (3). For simplicity of the ana lysis, the $\mathrm{C}$ PW s tructure was assumed $\mathrm{t} o$ be i nfinite i $\mathrm{nX}$ a nd $\mathrm{Z}$ di rections. Accordingly, the propagating mode was assumed to be TEM mode. Assuming a TEM mode, propagating a long $\mathrm{t}$ he $\mathrm{Z}$ di rection $\mathrm{w}$ ith pr opagation $\mathrm{c}$ onstant $\gamma_{\mathrm{z}}, \mathrm{t}$ hen $\mathrm{t}$ he 1 ongitudinal components for both electric and magnetic fields $\left(\mathrm{E}_{\mathrm{z}}\right.$ and $\left.\mathrm{H}_{\mathrm{z}}\right)$ are zero. Maxwell's equations can be written as

$$
\begin{aligned}
& H_{x}=-\frac{\gamma_{z}}{-j \omega \mu_{o} \mu} E_{y} \\
& H_{y}=-\frac{\gamma_{z}}{j \omega \mu_{o}} E_{x} \\
& \left(\gamma_{z}^{2}+\omega^{2} \mu_{o} \varepsilon_{o} \varepsilon_{r}\right) E_{x}=0 \\
& \left(\gamma_{z}^{2}+\omega^{2} \mu_{o} \varepsilon_{o} \mu \varepsilon_{r}\right) E_{y}=0
\end{aligned}
$$

From above equations, there are two possible solutions assuming either the field component $E_{y}$ or $E_{x}$ is zero.

\section{A- Solution (1)}

This solution is based on that $E_{y}=0$. In this case, the following results are valid:

$$
\begin{aligned}
& \bar{E}=E_{o} e^{\gamma_{Z}{ }^{z}} a_{x} \\
& \bar{H}=-\frac{\gamma_{z} E_{O}}{j \omega \mu_{O}} e^{\gamma_{Z}{ }^{z}} a_{y} \\
& \gamma_{z}=j \frac{\omega}{c} \sqrt{\varepsilon_{r}}
\end{aligned}
$$

where $E_{o}$ is the e lectric field component magnitude. The constants $a_{x}$ and $a_{y}$ are two unit vectors in the $X$ and $Y$ directions, respectively. From the field components derived in (13) and 
(14), it is clear that this solution presents a TEM mode. The propagation constant shown in

(15) indicates that this mode is independent on the magnetic properties of ferrite substrate.

\section{B- Solution (2)}

This solution is based on that $E_{x}=0$. In this case, the following results are valid:

$$
\begin{aligned}
& \bar{E}=E_{o} e^{\alpha_{X}{ }^{x}} e^{\gamma_{Z} z} \hat{a}_{y} \\
& \bar{H}=E_{o} \frac{\gamma_{z}}{-j \omega \mu_{O} \mu} e^{\alpha_{X} x} e^{\gamma_{Z}{ }^{z}} \hat{a}_{x} \\
& \gamma_{z}=j \frac{\omega}{c} \sqrt{\mu \varepsilon_{r}} \\
& \alpha_{x}=j \frac{k}{\mu} \gamma_{z}
\end{aligned}
$$

where $E_{o}$ is the electric field component magnitude. The field components obtained in (16) and (17) demonstrate the TEM propagation nature of this solution. Also, these two equations illustrate propagation along the $\mathrm{Z}$ direction with attenuation along the $\mathrm{X}$ direction, parallel to the D C m agnetic bi as direction. B oth of the propagation c onstant and the a ttenuation one given in (18) and (19), respectively, are dependent on the ferrite tensor permeability element $(\mu)$ that is given in (4). The dispersive nature of $(\mu)$ causes the propagating mode to be an evanescent mode $w$ hen the ferrite tensor pe rmeability is ne gative. Also, the propagation is lossless along the s trip $\mathrm{w}$ idth, a long $\mathrm{X}$ di rection, $\mathrm{w}$ ith a di spersive a ttenuation $\mathrm{c}$ onstant according to the value of the ferrite relative permeability tensor element $(\mu)$.

It can be concluded that for a positive permeability tensor element, a propagating wave will appear at the end of the ferrite C PW TL. But, for ne gative pe rmeability, no out put signal exists, $\mathrm{i}$ nstead the pow er i s t ransformed a long the $\mathrm{s}$ trip $\mathrm{w}$ idth di rection; $\mathrm{i}$.e. no $\mathrm{s}$ ignal is reflected back.

Similar results for the TEM propagation along a vertically biased ferrite CPW TL, shown in Figure 1 (b) can be obtained with interchanging the field components.

Consequently, the effective relative ferrite pe rmeability for nor mal DC magnetic bi as $\left(\mu_{f n}\right)$ and hence its negative values frequency band $\left(f_{n l}<f<f_{n h}\right)$ can be given as

$$
\begin{aligned}
& \mu_{f n}=\mu \\
& f_{n l}=\frac{1}{2 \pi} \omega_{h} \\
& f_{n h}=\frac{1}{2 \pi} \omega_{h m}
\end{aligned}
$$

\section{Full Wave Simulations}

The af orementioned theoretical s tudy ha $\mathrm{s}$ be en ve rified by s imulating the tr ansmission characteristics of a f errite C PW T L us ing the e lectromagnetic $\mathrm{f}$ ull $\mathrm{w}$ ave s imulation for different DC magnetic bias values. The commercial software ANSOFT- HFSS was employed in the simulation. The two possible normal magnetization directions have been examined. The examined ferrite CPW TL in both c ases has a strip width $\mathrm{W}=3.12 \mathrm{~mm}$, a s lot width $\mathrm{S}=1.2$ 
$\mathrm{mm}$, and a total length of $10 \mathrm{~mm}$. The substrate thickness is $\mathrm{h}=1 \mathrm{~mm}$ and the ferrite substrate has saturation magnetization $4 \pi \mathrm{M}_{\mathrm{S}}=1780$ Gauss.

First, assuming that a uniform int ernal ma gnetic field $\mathrm{H}_{0}$ is applied hor izontally to a ferrite CPW TL as shown in Figure 1 (a), the simulated transmission characteristics are shown in Figure 2 . For $\mathrm{H}_{0}=0$ Oe, in Figure 2 (a), the figure $\mathrm{s}$ hows $\mathrm{t}$ hat $\mathrm{t}$ he 1 ine ha $\mathrm{s}$ no $\mathrm{s}$ topband propagation. $\mathrm{T}$ he a bsence of $\mathrm{t}$ he $\mathrm{s}$ topband $\mathrm{c}$ onfirms $\mathrm{t}$ he a nalytically de rived ne gative permeability calculation formula introduced in equations (16) to (19) that predicts no negative permeability values for zero internal DC magnetic bias.

For $\mathrm{H}_{0}=500 \mathrm{O}$, analytically, the cal culated negative pe rmeability frequency $\mathrm{b}$ andwidth for this D C ma gnetic bi as v alue, from (20), is within $1.4 \mathrm{G} \mathrm{Hz}$ to $3.1 \mathrm{GHz}$. For this case, the simulated transmission characteristics are shown in Figure 2 (b). In the figure, the ferrite TL exhibits a $0 \mathrm{~dB}$ insertion 1 oss $t$ ransmission $w$ ithin the $w$ hole $s$ tudied frequency $b$ andwidth except from $2 \mathrm{GHz}$ to $6.4 \mathrm{GHz}$, imperfect transmission within this frequency band. The ferrite TL has almost reciprocal lossy propagation, with transmission coefficient level between 0 and $-3 \mathrm{~dB}$, within the frequency band from $2 \mathrm{GHz}$ to $2.6 \mathrm{GHz}$. Then, it demonstrates a significant nonreciprocal stopband within the frequency band from $2.6 \mathrm{GHz}$ to $3.2 \mathrm{GHz}$. This stopband is characterized by bot $h$ of low $r$ eflection coefficient, almost be tter tha $n-10 \mathrm{~dB}$, and $1 \mathrm{ow}$ transmission coefficient, lower than $-10 \mathrm{~dB}$ for $\mathrm{S}_{12}$ magnitude. Finally, the TL has a reciprocal lossy propagation in the bandwidth that extends from $3.6 \mathrm{G} \mathrm{Hz}$ to $6 \mathrm{GHz}$. By comparing the nonreciprocal $\mathrm{s}$ topband bandwidth $\mathrm{w}$ ith the a nalytically $\mathrm{c}$ alculated ba ndwidth of ne gative permeability, we can comment that the ana lytical cal culation can predict to high degree of accuracy the uppe $\mathrm{r} \mathrm{c}$ ut of $\mathrm{f}$ frequency of $\mathrm{s}$ imulated nonr eciprocal $\mathrm{s}$ topband. $\mathrm{H}$ owever, i $\mathrm{t}$ introduces a lower shift for the lower cut off frequency.

Similar results can be obtained for $\mathrm{H}_{0}=1000 \mathrm{Oe}$ and $2000 \mathrm{O}$ e, as shown in Figure 2 (c) and (d), respectively. For $\mathrm{H}_{0}=1000 \mathrm{Oe}$, the whole imperfect transmission bandwidth extends from $3.3 \mathrm{GHz}$ to $7.8 \mathrm{GHz}$ where its nonreciprocal stopband is within the frequency band $3.8 \mathrm{GHz}$ to $4.7 \mathrm{G} \mathrm{Hz}$. A lso, it is noted that i ts lower c ut off frequency, $3.8 \mathrm{G} \mathrm{Hz}$, is hi gher than the analytically calculated one, $2.8 \mathrm{GHz}$ whereas its upper cut off frequency, $4.7 \mathrm{GHz}$ is close to the a nalytically calculated one, $4.8 \mathrm{G} \mathrm{Hz}$. F or $\mathrm{H}_{0}=2000 \mathrm{O}$ e, the s imulated nonr eciprocal propagation stopband is within $6.5 \mathrm{G} \mathrm{Hz}$ to $7.7 \mathrm{G} \mathrm{Hz}$ while the analytically calculated one is within $5.6 \mathrm{GHz}$ to $7.7 \mathrm{GHz}$.

It can be seen from these two cases that low levels for both of the reflection coefficient $\left(\mathrm{S}_{11}\right)$ and $t$ he $t$ ransmission $c$ oefficients $\left(S_{12}\right.$ and $\left.S_{21}\right) w$ ithin the ne gative $f$ errite $p$ ermeability stopband de crease by i ncreasing the DC m agnetic bi as va lue. Also, it is obs erved that the nonreciprocal propagation properties become more significant by increasing the DC magnetic bias.

From a $11 \mathrm{t}$ he a bove $\mathrm{s}$ tudied $\mathrm{c}$ ases, $\mathrm{w}$ e $\mathrm{c}$ an $\mathrm{c}$ onclude $\mathrm{t}$ hat $\mathrm{t}$ he $\mathrm{f}$ errite $\mathrm{T} \mathrm{L}$ ha $\mathrm{s}$ ne gative permeability within the frequency bandwidth whose lower cut off frequency is slightly higher than $f_{n l}$ defined in (21) and $i$ ts uppe $r \mathrm{c}$ ut of $f$ f requency coincides a pproximately $w$ ith $f_{n h}$ defined i $\mathrm{n}$ (22). $\mathrm{T}$ his ve rifies $\mathrm{t}$ he T EM $\mathrm{m}$ athematical ana lysis i ntroduced above $\mathrm{f}$ or $\mathrm{t}$ he horizontal DC magnetic bias direction. The variations of $\mathrm{cut}$ of $\mathrm{f}$ frequencies a re due to the approximation done in the analytical calculation. 


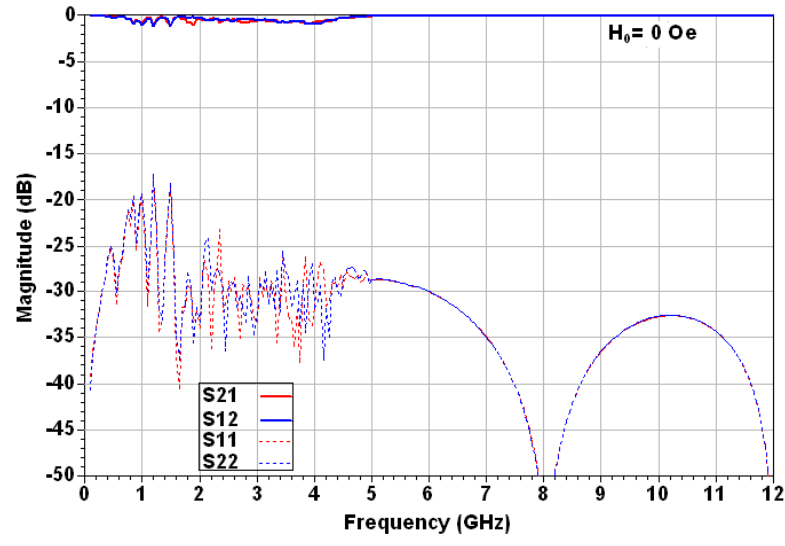

(a)

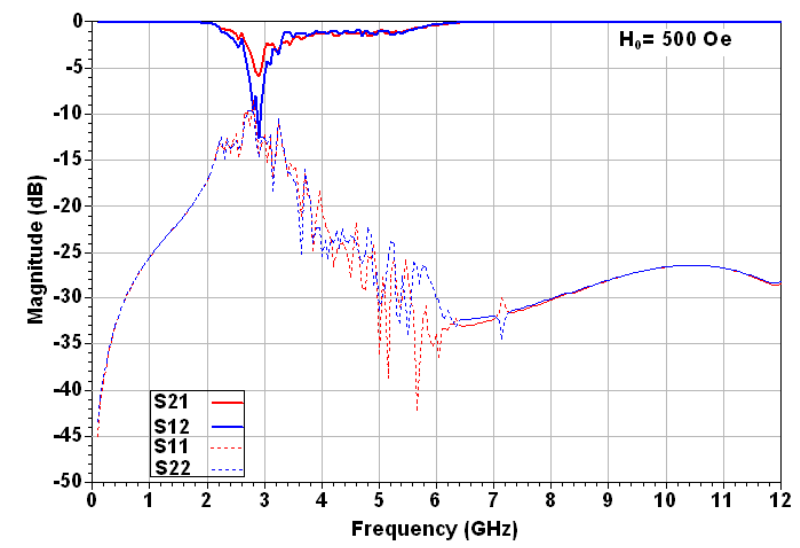

(b)

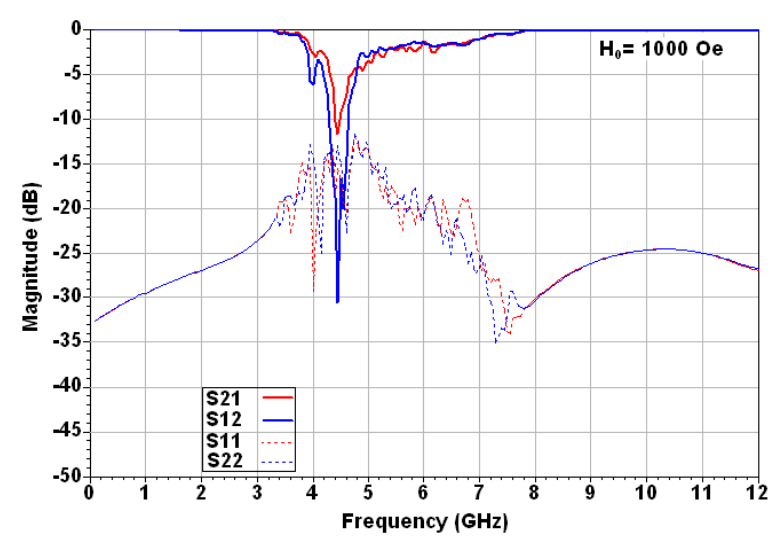

(c)

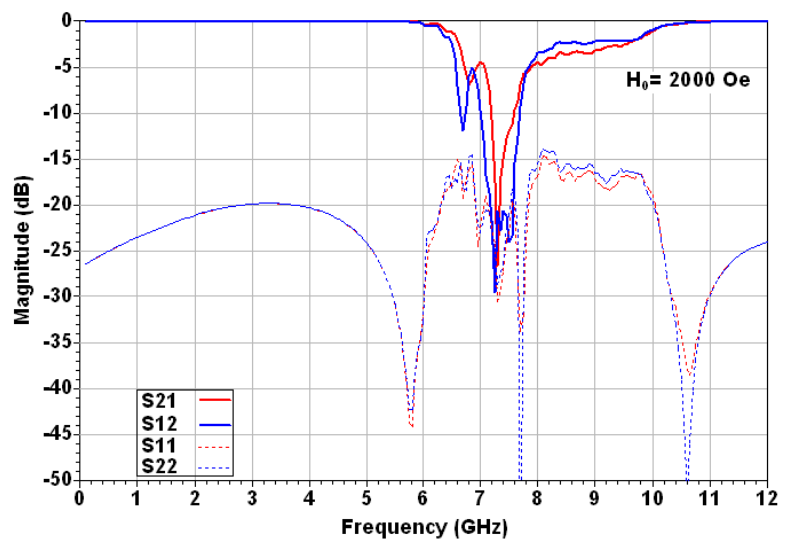

(d)

Figure 2 The full wave scattering parameter magnitudes of the ferrite CPW TL for (a) $\mathrm{H}_{0}=0$ Oe, (b) $\mathrm{H}_{0}=500$ Oe, (c) $\mathrm{H}_{0}=1000$ Oe, and (d) $\mathrm{H}_{0}=2000$ Oe horizontal biased.

The second step in the numerical study is to verify the vertically magnetized ferrite CPW TL analytical s tudy. Thus, the same ferrite C PW T L w ith vertical ma gnetization is simulated using HFSS for the same DC magnetic bias values as shown in Figure 3. It is worth to repeat that the ve rtically magnetized ferrite C PW T L has the analytically de rived de finition of relative permeability in (20), similar to the horizontal magnetization case.

First, for $\mathrm{H}_{0}=0$ Oe, it is clear from its simulated scattering parameters in Figure 3 (a), that the ferrite C PW T L h as no stopband propagation. This confirms the theoretical analysis of the vertically magnetized ferrite CPW TL which implies that its relative permeability, defined in (20),), is always positive for zero DC magnetic bias.

Next, the simulated scattering magnitudes for $\mathrm{H}_{0}=500 \mathrm{Oe}, 1000 \mathrm{O}$ e, and $2000 \mathrm{O}$ e are shown in Figure 3 (b), (c), and (d), respectively. A s s hown in theses figures, the ferrite C PW T L illustrates di spersive lossy pr opagation $\mathrm{w}$ ith $\mathrm{c}$ lear $\mathrm{s}$ topband a nd insignificant nonr eciprocal properties for all theses cases. For $\mathrm{H}_{0}=500 \mathrm{Oe}$, the whole imperfect transmission extends from $1.5 \mathrm{GHz}$ to $5 \mathrm{GHz}$ with higher insertion loss within the frequency band from $1.8 \mathrm{GHz}$ to 2.5 GHz. For $\mathrm{H}_{0}=1000 \mathrm{Oe}$, the whole imperfect transmission extends from $2.8 \mathrm{G} \mathrm{Hz}$ to $7.4 \mathrm{G} \mathrm{Hz}$ with hi gher insertion loss within the frequency band from $3.2 \mathrm{G} \mathrm{Hz}$ to $4 \mathrm{G} \mathrm{Hz}$. F inally, for $\mathrm{H}_{0}=2000 \mathrm{Oe}$, the whole imperfect transmission extends from $5.4 \mathrm{GHz}$ to $10 \mathrm{GHz}$ with higher insertion loss within the frequency band from $5.6 \mathrm{GHz}$ to $7.3 \mathrm{GHz}$. 
From $\mathrm{t}$ hese $\mathrm{s}$ tudied $\mathrm{c}$ ases, $\mathrm{w}$ e $\mathrm{c}$ an conclude $\mathrm{t}$ hat, $\mathrm{t}$ he $\mathrm{i}$ ntroduced $\mathrm{s}$ ignificant $\mathrm{s}$ topband i $\mathrm{s}$ characterized by 1 ow $\mathrm{r}$ eflection and transmission coefficients, similar to the hor izontal magnetization ferrite CPW TL case. However, in comparison with horizontal magnetization, the ve rtical $\mathrm{c}$ ase ha s hi gher r eflection coefficient and higher transmission coefficients. By comparing the stopband ba ndwidth, with the ana lytically cal culated bandwidth of ne gative permeability, we observe that the analytical calculation introduces both positive and negative shifts for the lower and upper cut off frequencies of the simulated stopbands, respectively. It is observed that these two shifts decrease, specially the positive shift, by increasing the DC magnetic bias values. For $\mathrm{H}_{0}=2000$ Oe the analytically derived permeability is expected to be negative starting from $5.6 \mathrm{GHz}$, which coincides exactly with the numerical found value, and lasting to $7.7 \mathrm{GHz}$ which is $0.4 \mathrm{GHz}$ higher that the numerically found one.

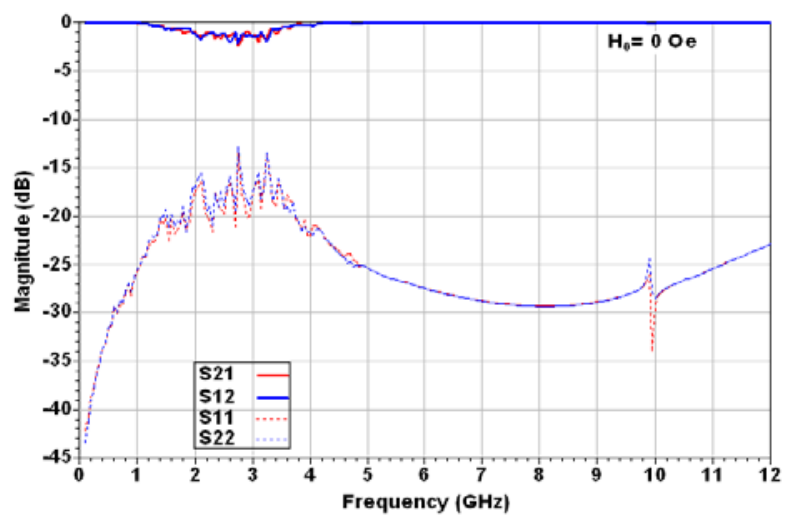

(a)

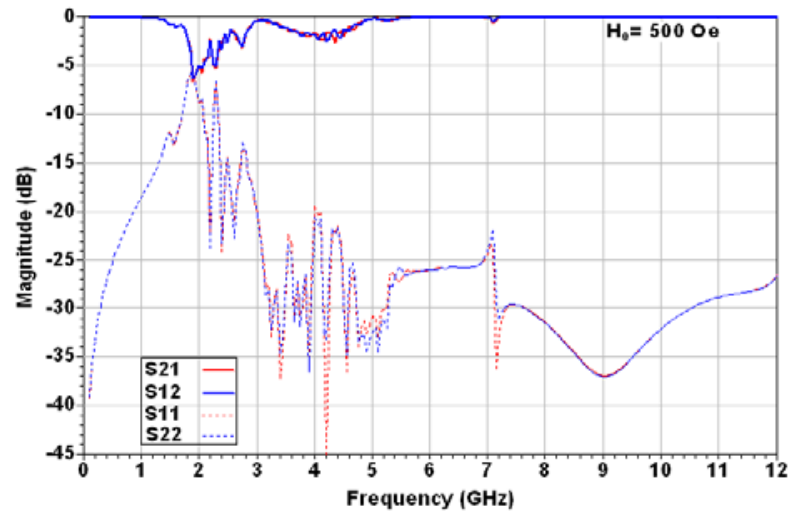

(b)

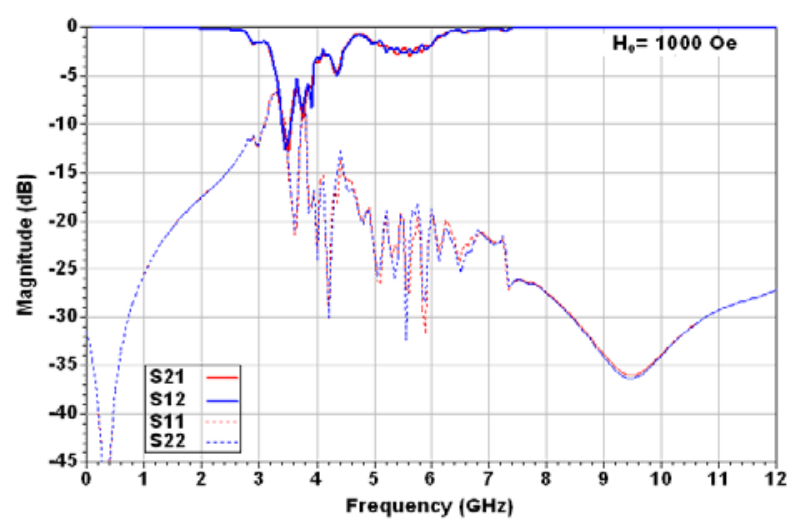

(c)

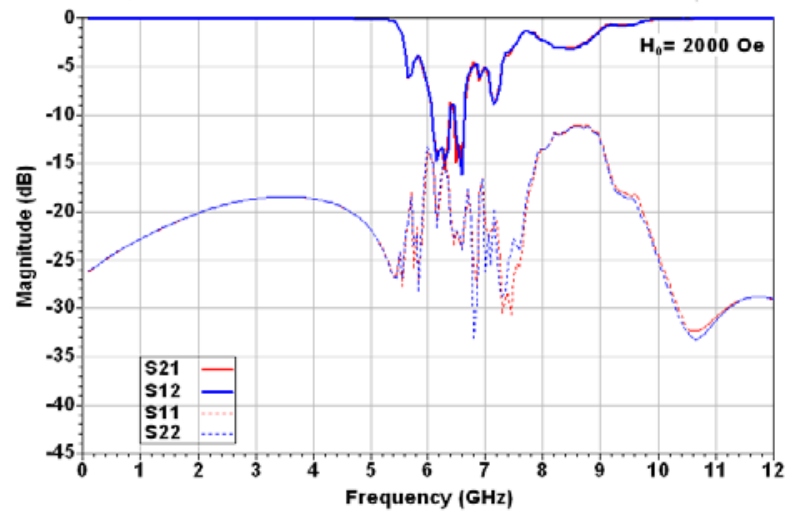

(d)

Figure 3 The full wave scattering parameter magnitudes of the ferrite CPW TL for (a) $\mathrm{H}_{0}=0$ Oe, (b) $\mathrm{H}_{0}=500$ Oe, (c) $\mathrm{H}_{0}=1000$ Oe, and (d) $\mathrm{H}_{0}=2000$ Oe vertically biased.

\section{TEM Mode Propagation in a Longitudinally Magnetized Ferrite CPW TL}

In $t$ his s ection, $w$ e pr esent $t$ he $s$ tudy of $t$ he 1 ongitudinally bi ased $f$ errite $C$ PW T L, i . e . magnetized a long the di rection of p ropagation. T he front vi ew of the ferrite C PW T L is shown in Figure 4. First, we introduce its mathematical analysis and then this analysis will be verified numerically by studying its scattering parameters. 


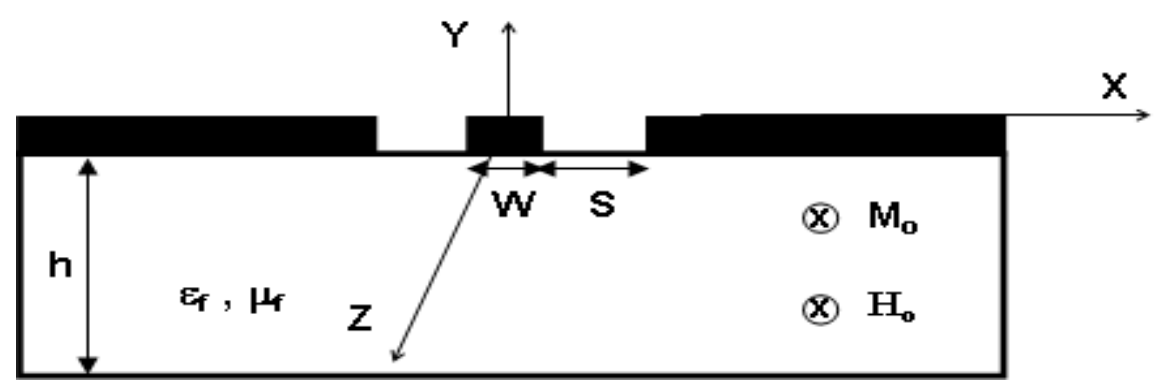

Figure 4 The front view of the ferrite CPW TL, longitudinally magnetized.

\section{TEM Mathematical Analysis}

The $m$ athematical ana lysis of the 1 ongitudinally m agnetized ferrite C PW T L can be done similar to the aforementioned analysis for normal biased ferrite CPW TL using the full wave analysis technique. For this DC magnetic bias, the permeability tensor of CPW transmission line biased in $\mathrm{Z}$ direction defined in (1).

Similar to nor mal a nalysis, a ssume a T EM m ode, pr opagating a long the $\mathrm{Z}$ di rection $\mathrm{w}$ ith propagation $\mathrm{c}$ onstant $\gamma_{\mathrm{z}}$, $\mathrm{t}$ hen $\mathrm{t}$ he 1 ongitudinal $\mathrm{c}$ omponents $\mathrm{f}$ or bot $\mathrm{h}$ e lectric a nd $\mathrm{m}$ agnetic fields $\left(\mathrm{E}_{\mathrm{z}}\right.$ and $\left.\mathrm{H}_{\mathrm{z}}\right)$ are zero. Thus, Maxwell's equations can be written as

$$
\begin{aligned}
& H_{x}=-\frac{j \omega \varepsilon}{\gamma_{z}} E_{y} \\
& H_{y}=\frac{j \omega \varepsilon}{\gamma_{z}} E_{x} \\
& \left(-j \omega^{2} \mu_{o} \varepsilon_{o} \varepsilon_{r} k\right) E_{x}+\left(\gamma_{z}^{2}+\omega^{2} \mu_{o} \mu \varepsilon_{o} \varepsilon_{r}\right) E_{y}=0 \\
& \left(\gamma_{z}^{2}+\omega^{2} \mu_{o} \mu \varepsilon_{o} \varepsilon_{r}\right) E_{x}+\left(j \omega^{2} \mu_{o} \varepsilon_{o} \varepsilon_{r} k\right) E_{y}=0
\end{aligned}
$$

Solving the two equations set (25) and (26), we can find that there are two possible solutions with two different propagation constants; which can expressed as

$$
\begin{aligned}
& \gamma_{z 1}=j \omega \sqrt{\mu_{o} \varepsilon_{o} \varepsilon_{r}(\mu-k)} \\
& \gamma_{z 2}=j \omega \sqrt{\mu_{o} \varepsilon_{o} \varepsilon_{r}(\mu+k)}
\end{aligned}
$$

The two electric field components $\left(E_{1}\right)$ and $\left(E_{2}\right)$, associated with $\gamma_{\mathrm{z} 1}$ and $\gamma_{\mathrm{z} 2}$, respectively, are

$$
\begin{aligned}
& E_{1}=E_{o}\left(\hat{a}_{x}-j \hat{a}_{y}\right) e^{-\gamma_{z 1} z} \\
& E_{2}=E_{o}\left(\hat{a}_{x}+j \hat{a}_{y}\right) e^{-\gamma_{z 2} z}
\end{aligned}
$$

where $E_{o}$ is the electric field component magnitude. The final expression for the propagated electric field components in (29) and (30), confirms that propagation is TEM mode. Also, it can be $\mathrm{c}$ laimed $\mathrm{t}$ hat $\mathrm{t}$ he pr opagation $\mathrm{m}$ ode $\mathrm{h}$ as 1 ossless pr opagation constant a long $\mathrm{t}$ he propagation di rection $(Z)$. However, this propagation c onstant is de pendent on bot $h$ of the 
ferrite tensor parameters $\mu$ and $k$ given in (4) and (5), respectively. Therefore, it is expected that the propagation $\mathrm{w}$ ill have a di spersive na ture ba sed on the a pplied DC m agnetic bi as value. On contrast to the normal DC magnetic bias case explained previously, the propagation has no a ttenuation a long DC m agnetic bi as direction. In ot her words, for pos itive effective permeability frequency band, 1 ossless propagation a long the $\mathrm{T} L$ exists. $\mathrm{B}$ ut, f or ne gative permeability frequency band, no propagation along that direction and the input signal will be reflected back.

A formula for the effective relative ferrite permeability of longitudinal magnetization can be defined using duality with the longitudinal magnetized ferrite microstrip TL [5] or ferrite slab [6] as

$\mu_{f p}=\frac{\mu^{2}-k^{2}}{\mu}=\frac{\left(\omega_{h}+\omega_{m}\right)^{2}-\omega^{2}}{\omega_{h m}^{2}-\omega^{2}}$

It is shown that the effective permeability has a dispersion nature whose value is negative or positive depending on the properties of the ferrite substrate and the applied DC magnetic bias. This equivalent permeability will be negative values for the frequency range $f_{p l}<f<f_{p h}$ given as follow

$$
\begin{aligned}
& f_{p l}=\frac{1}{2 \pi} \omega_{h m} \\
& f_{p h}=\frac{1}{2 \pi}\left(\omega_{h}+\omega_{m}\right)
\end{aligned}
$$

\section{Full Wave Simulation}

The the oretical study of longitudinally magnetized ferrite CPW TL was verified numerically by simulating such TL using HFSS. The simulated ferrite CPW TL has the same dimensions and ferrite substrate properties as assumed in the normal magnetization analysis. It is noted that, the de finition of the r elative pe rmeability of long itudinal ma gnetized case is $\mathrm{g}$ iven in (31).

The simulating scattering parameters for such TL for different DC magnetic bias values are shown in Figure 5. From the figure, it can be observed that the ferrite CPW TL illus trates dispersive non pr opagation bandwidths w ith very dominant $s$ topband and a lmost reciprocal properties f or a $11 \mathrm{~s}$ tudied $\mathrm{c}$ ases, i ncluding $\mathrm{H}_{0}=0 \mathrm{O}$ e $\mathrm{c}$ ase. A lso, unl ike the $\mathrm{t}$ wo nor mally magnetized cases, this s topband is characterized by both of very high reflection coefficient and low transmission coefficient. Approximately, at centre frequencies of such stopband, the reflection coefficient is higher than $-5 \mathrm{~dB}$ in all $\mathrm{c}$ ases $\mathrm{w}$ hile the transmission coefficient is lower than $-25 \mathrm{~dB}$ in all cases except zero bias case where it is a bit lower than $-10 \mathrm{~dB}$.

The $\mathrm{s}$ imulated scattering parameters for $\mathrm{H}_{0}=0 \mathrm{O}$ e is s hown in Figure 5 (a). Unlike, to the normal magnetized cases, a significant stopband exists in the frequency band $1.7 \mathrm{GHz}$ to 3.25 $\mathrm{GHz}$ w ith almost $-5 \mathrm{~d} \mathrm{~B} \mathrm{r}$ eflection $\mathrm{c}$ oefficient. W ithin $\mathrm{t}$ his $\mathrm{s}$ topband $\mathrm{t}$ he $\mathrm{t}$ ransmission coefficient are below $-5 \mathrm{~dB}$ and it goes below $-15 \mathrm{~dB}$ at $2.8 \mathrm{GHz}$. Below this stopband, from 1 $\mathrm{GHz}$ to $1.7 \mathrm{G} \mathrm{Hz}$, and hi gher than it, from $3.25 \mathrm{G} \mathrm{Hz}$ to $5 \mathrm{G} \mathrm{Hz}$, the T L demonstrates lossy propagation $w$ ith $t$ ransmission c oefficient 1 ower $t$ han $-5 \mathrm{~dB}$ and app roximately $-10 \mathrm{~d} B$ reflection level. The stopband appearance confirms the permeability definition in (31) which implies that it is negative for zero longitudinal DC magnetic bias within the frequency band 
from $\mathrm{f}_{\mathrm{pl}}=0 \mathrm{t}$ o $\mathrm{f}_{\mathrm{ph}}=5 \mathrm{GHz}$ as cal culated from (32) a nd (33), respectively. However, a significant va riation between these $t$ wo cut of $\mathrm{f}$ frequencies obt ained either ana lytically o $\mathrm{r}$ numerically which will be analyzed in more details for the higher DC magnetic bias cases.

The simulated scattering magnitudes for $\mathrm{H}_{0}=500 \mathrm{Oe}, 1000 \mathrm{Oe}$, and $2000 \mathrm{Oe}$ are shown in Figure 5 (b), (c), a nd (d), r espectively. A s s hown in the figures, the significant $\mathrm{s}$ topband extends from $3.4 \mathrm{G} \mathrm{Hz}$ to $6.4 \mathrm{G} \mathrm{Hz}$ for $\mathrm{H}_{0}=500 \mathrm{Oe}$, from $4.7 \mathrm{G} \mathrm{Hz}$ to $7.7 \mathrm{G} \mathrm{Hz}$ for $\mathrm{H}_{0}=1000$ $\mathrm{Oe}$, a nd from $7.4 \mathrm{G} \mathrm{Hz}$ to $10.6 \mathrm{G} \mathrm{Hz}$ for $\mathrm{H}_{0}=2000 \mathrm{O}$ e. All these stopbands have $\mathrm{S}_{11}$ level higher $\mathrm{t}$ han $-5 \mathrm{~dB}$ a nd very low reciprocal $\mathrm{S}_{21}$ level, reaches $-25 \mathrm{~dB}$ at cent re ope rating frequencies, frequencies of $\mathrm{m}$ aximum $\mathrm{r}$ eflection coefficient and minimum $\mathrm{t}$ ransmission coefficient. On $\mathrm{t}$ he ot her ha nd, a nalytically $\mathrm{d}$ erived ba ndwidth of ne gative pe rmeability $\left(\mathrm{f}_{\mathrm{pl}}<\mathrm{f}<\mathrm{f}_{\mathrm{ph}}\right)$ calculated from (32) and (33), respectively for these DC magnetic bi as values are as f ollow. For $\mathrm{H}_{0}=500 \mathrm{O}$ e, t his ba ndwidth e xtends f rom $3 \mathrm{G} \mathrm{Hz} \mathrm{t} \mathrm{o} 6.4 \mathrm{G} \mathrm{Hz}$, f or $\mathrm{H}_{0}=1000 \mathrm{Oe}$, it extends from $4.7 \mathrm{G} \mathrm{Hz}$ to $7.8 \mathrm{G} \mathrm{Hz}$, and it is from $7.7 \mathrm{GHz}$ to $10.6 \mathrm{GHz}$ for $\mathrm{H}_{0}=2000$ Oe.

By comparing the two bandwidth values, we $\mathrm{c}$ an conclude that the ferrite $\mathrm{T} L$ ha s $\mathrm{n}$ egative permeability within the frequency band whose lower cut off frequency is close to $f_{p l}$ defined in (32) while its upper cut off frequency coincides approximately with $\mathrm{f}_{\mathrm{ph}}$ defined in (33).

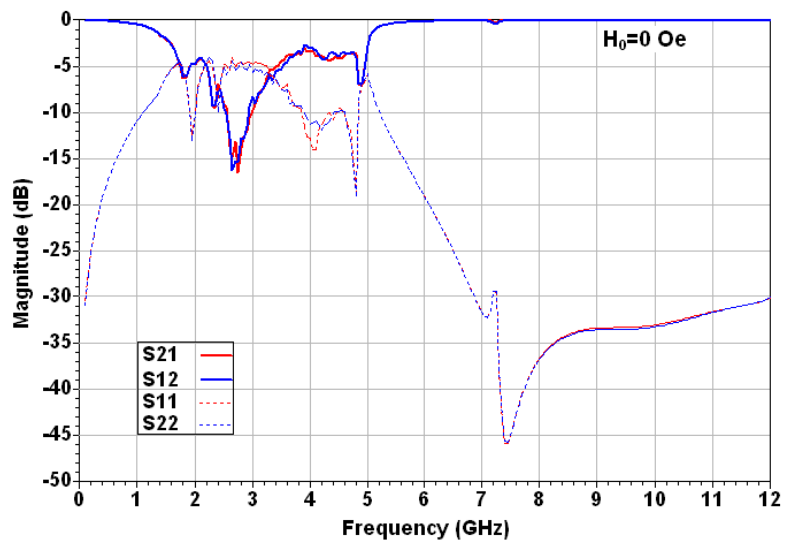

(a)

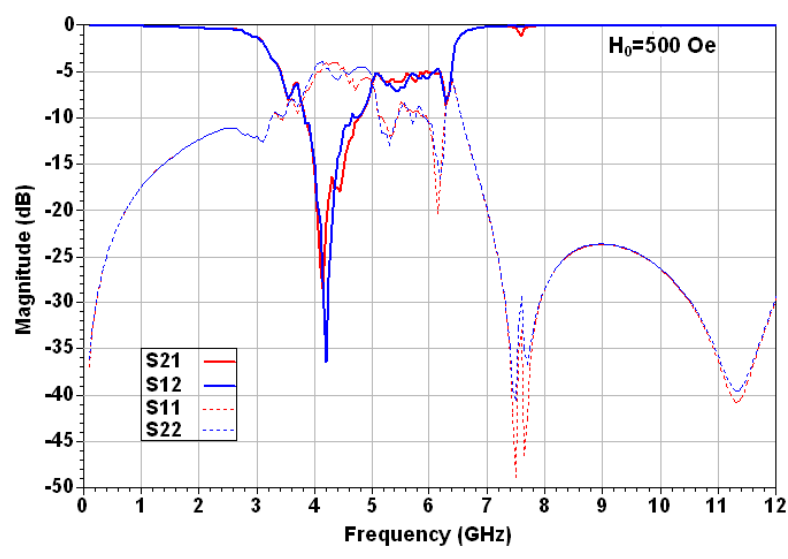

(b)

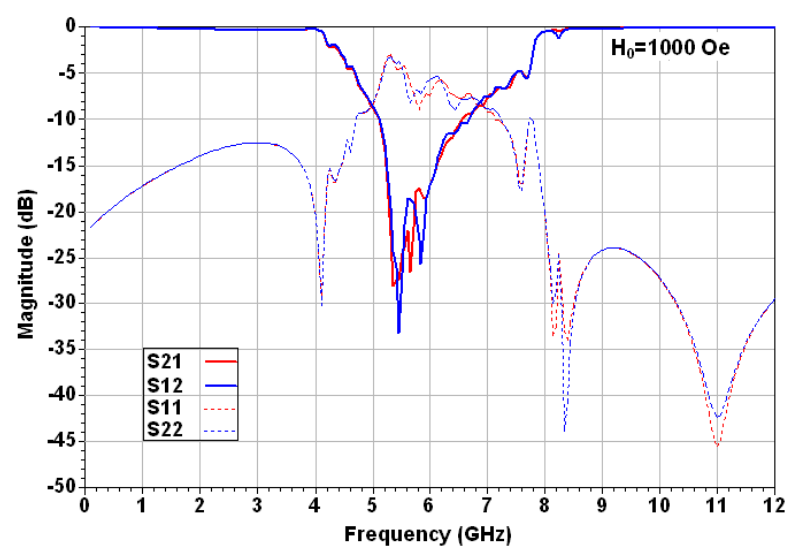

(c)

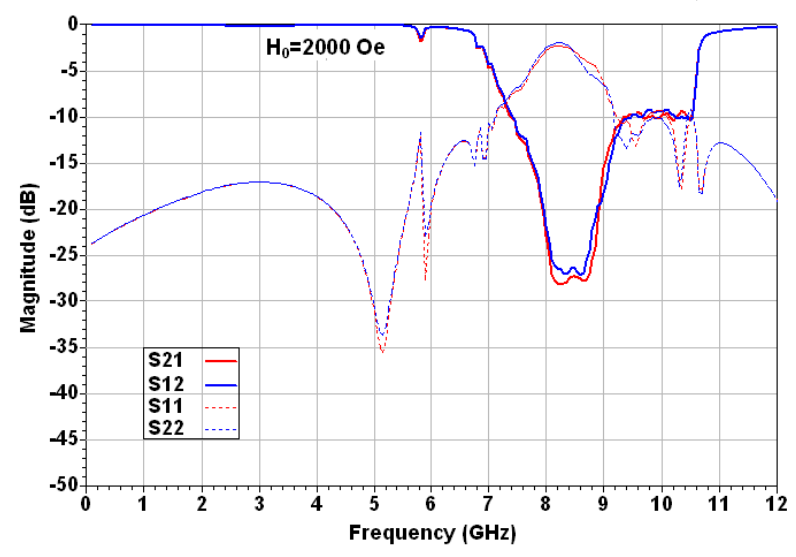

(d)

Figure 5 The full wave scattering parameter magnitudes of ferrite CPW TL for

(a) $\mathrm{H}_{0}=0$ Oe, (b) $\mathrm{H}_{0}=500$ Oe, (c) $\mathrm{H}_{0}=1000$ Oe, and

(d) $\mathbf{H}_{0}=2000$ Oe longitudinally biased. 


\section{References}

[1] M. E. Hines, "Reciprocal and nonreciprocal modes of propagation in ferrite stripline and microstrip de vices," IEEE Transactions on Microwave Theory and Techniques, vol. MTT-19, pp. 442-51, 1971.

[2] R. A. W aldron, Ferrites : an introduction for microwave engineers. New York: Va n Nostrand, 1962.

[3] D. M. Pozar, Microwave engineering. New York: J. Wiley \& Sons, 1998

[4] A. J. B . F uller, Ferrite at microwave frequencies. S tevenage, London: Institution of Engineering and Technology, 1987

[5] C. S. T eoh a nd L . E . D avis, " Normal-mode a nalysis of f errite-coupled 1 ines us ing microstrips or slotlines," IEEE Transactions on Microwave Theory and Techniques, vol. 43, pp. 2991-2998, 1995.

[6] G. Dewar, "A ne gative i ndex of $\mathrm{r}$ efraction metamaterial b ased on a w ire ar ray embedded in ferrite," presented at Complex Mediums VI: Light and Complexity, Jul 31Aug 2 2005, San Diego, CA, United States, 2005. 